\title{
RECONSTRUINDO O “ELO PERDIDO”: A RECONEXÃO DA PRODUÇÃO E DO CONSUMO DE ALIMENTOS ATRAVÉS DO PROGRAMA DE ALIMENTAÇÃO ESCOLAR NO MUNICÍPIO DE DOIS IRMÃOS (RS)
}

\begin{abstract}
Rozane Márcia Triches ${ }^{1}$ e Sergio Schneider ${ }^{2}$
Este artigo discute, a partir de um estudo de caso, como o Programa de Alimentação Escolar (PAE) foi utilizado para reconstruir as relações de produção e consumo. Seu objetivo consiste em refletir sobre uma experiência bem sucedida de construção de cadeias alimentares curtas no município de Dois Irmãos, Rio Grande do Sul/Brasil. A pesquisa foi realizada a partir de um estudo de caso que utilizou técnicas qualitativas de levantamento de dados por meio de entrevistas semiestruturadas (analisadas com o softwware NVivo 2.0), observação direta e dados secundários. O trabalho mostra como as políticas de atuação local podem constituirse em mecanismos de atendimento da demanda e apresentar-se como alternativas às falhas de mercados que afetam os pequenos agricultores familiares que ficam alijados do acesso às compras públicas em razão de regulamentações, processos licitatórios e exigências legais e sanitárias que obstaculizam sua formalização como fornecedores. Para tanto, destaca a importância da participação dos atores locais. A conclusão indica que o PAE pode ser considerado um instrumento efetivo de redesenho das políticas locais de abastecimento e apresenta efeitos positivos para consumidores e fornecedores, além de permitir que os atores da sociedade civil apropriem-se do próprio processo de execução das políticas públicas, via participação em Conselhos.
\end{abstract}

Palavras- chave: alimentação escolar, segurança alimentar e nutricional, saúde pública, agricultura familiar, desenvolvimento rural.

\section{THE RECONSTRUCTION OF THE "MISSING LINK": RECONNECTING PRODUCTION AND CONSUMPTION FOOD RELATIONS THROUGH THE SCHOOL FEEDING PROGRAM IN THE COUNTY OF DOIS IRMÃOS (RS)}

\begin{abstract}
This article discusses, how the Brazilian School Feeding Program (SFP) could be understood as a device to reconstruct the production and consumption relations. The paper was drawn from a successful experience that occurred in a small municipality of Dois Irmãos, Rio Grande do Sul, South Brazil, where a social processes of construction of short food supply chains and reconfiguration of the school food procurement took place. The research was led through a case study and used qualitative techniques of data collection through semi-structured interviews (analyzed with the software NVivo 2.0.), direct observation and secondary data information. The authors show how local policies operations, such as PAE, can constitute a mechanism to support the demand and presenting themselves as alternatives to market failures that affect the small farmers which are often priced out of access to public procurement because of regulations, tendering procedures, legal and health requirements which hinder their formalization as suppliers. The study highlights the importance that had the active participation of local stakeholders in the implementation. The finding indicates that the SFP can be considered an effective instrument of policy redesign refueling and has positive effects for consumers (students) and suppliers (farmers), beyond to allows the actors of civil society learn about the process of public policies implementation, through their participation in the municipal council.
\end{abstract}

Key words: school feeding, food and nutrition security, public health, family farming, rural development.

\footnotetext{
${ }^{1}$ Doutora em Desenvolvimento Rural - Universidade Federal do Rio Grande do Sul - UFRGS - Rua Berlim, 240, Dois Irmãos, RS. CEP. 93950.000 - Tel./Fax: (51)35641277.E-mail: rmtriches@terra.com.br

${ }^{2}$ Professor do Programa de Pós-Graduação em Desenvolvimento Rural (PGDR) e membro do Programa de Pós-Graduação em Sociologia (PPGS) da Universidade Federal do Rio Grande do Sul. Av. João Pessoa, 31, Porto Alegre, RS. 90040-000. E-mail: schneide@,ufrgs.br
} 


\section{Introdução}

No Brasil, vem ocorrendo uma complexa trama no que diz respeito à questão alimentar e nutricional da população. Nas últimas décadas vêm se observando um fenômeno chamado de "transição nutricional", caracterizado por um aumento dos índices de sobrepeso e de doenças crônicas não transmissíveis, associados ainda a uma grande, mas declinante, prevalência de déficits nutricionais. Segundo a Pesquisa de Orçamentos Familiares (POF) de 2002-2003, a população adulta brasileira não estava mais exposta aos riscos de desnutrição, sendo a taxa de 4\% compatível com os padrões internacionais, uma proporção esperada de indivíduos que são constitucionalmente magros. Por outro lado, a mesma pesquisa apontou que o excesso de peso afetava $41,1 \%$ dos homens e $40,0 \%$ das mulheres. Em 1997, na população de seis a 18 anos, os índices de sobrepeso praticamente triplicaram em relação a 1975 , alcançando a prevalência de $13,9 \%$ nesta faixa etária [1]. No entanto, apesar do acréscimo de doenças resultantes da má alimentação, do excesso alimentar e da tendência de mudança do perfil nutricional da população, a fome e a insegurança alimentar ainda permaneceram elevadas, conforme a primeira pesquisa sobre Segurança Alimentar no País, realizada em 2004 pelo Instituto Brasileiro e Geografia e Estatística (IBGE), que revelou que 34,8\% dos domicílios estavam em situação de insegurança alimentar (IA).

$\mathrm{Na}$ esfera da produção, soma-se o fortalecimento de um modelo produtivo agroalimentar assentado na agricultura intensiva, mecanizada e com elevada utilização de produtos químicos. Paradoxalmente, é a agricultura familiar que responde por parte considerável do abastecimento interno de alimentos. O Censo Agropecuário de 2006 apontou para uma tendência ascendente nesse sentido, com menor importação de alimentos devido ao rápido acréscimo de produtividade e maior aproveitamento das terras por esse tipo de estabelecimento ${ }^{3}$. Dessa forma, pode-se dizer que a produção de gêneros que compõem a dieta alimentar básica da população advém, principalmente, desse segmento da agricultura, que oferece grande contrapartida à produção nacional [2].

Para fazer frente às tendências citadas, na última década, o Estado tem abordado modelos estruturantes pautados nos conceitos de Segurança Alimentar e Nutricional Sustentável (SAN). Essas políticas

3 Segundo dados do Censo Agropecuário de 2006, os estabelecimentos rurais de tipo familiar perfazem $84,4 \%$ do total de estabelecimentos rurais e ocupam somente $24,3 \% \mathrm{da}$ área total, relevando uma grande disparidade de acesso a terra. constituem-se a partir de dois componentes básicos: o componente alimentar, relacionado à produção, à disponibilidade, à comercialização e ao acesso ao alimento; e, o componente nutricional, relacionado às práticas alimentares e à utilização biológica do alimento, e, portanto ao estado de nutrição da população. Propõem assim, um modelo mais sustentável, que aproxime a produção de pequenos agricultores familiares e o consumo de alimentos, contribuindo para uma reconexão da cadeia alimentar e uma relação mais estreita entre campo e cidade.

Nessa perspectiva, as aquisições públicas alimentares para o Programa de Alimentação Escolar (PAE) surgem como potenciais reintegradores desses componentes, tendo condições de auxiliar no enfrentamento das problemáticas referentes ao consumo e à produção de alimentos. Por um lado, integram políticas de direito à alimentação, relacionadas à saúde e à nutrição da população de escolares e, por outro, criam mercados para os agricultores familiares onde não existiam ou eram muito débeis.

Essa percepção do Estado fortalece-se por meio de iniciativas como a recém-publicada Medida Provisória no 455 de 21/01/2009, que passa a ter forma de lei em 16 de junho do mesmo ano - Lei no 11.947 , regulamentada um mês após pela Resolução no 38. Essa Lei torna-se um marco nas políticas públicas relativas à SAN. Em primeiro lugar, porque ampara, explicitamente, a agricultura familiar, tornando obrigatória a utilização de no mínimo $30 \%$ do valor remetido às entidades executoras pelo FNDE na aquisição de gêneros alimentícios desses fornecedores (em 2010, a previsão de recursos alocados pelo governo federal é de três bilhões de reais para 47 milhões de alunos). Em segundo lugar, porque é uma inovação no que diz respeito à legislação das aquisições públicas brasileiras. Se, até então, todas as compras estavam sob a obrigatoriedade de seguir os preceitos legais de isonomia e concorrência, abre-se um precedente histórico para o fornecedor caracterizado como "agricultor familiar": dispensa-se o processo licitatório, como disposto no seu artigo 14. A sanção dessa Lei coroa a revisão da legislação do Programa, que, juntamente com o aumento dos recursos estatais alocados e com a maior abrangência da população atendida, reflete a revisão na regulação política do País desde 2003.

No que concerne à efetivação dessa política em nível local, poucas iniciativas tinham sido observadas até a obrigatoriedade legal. Apesar dos cinquenta anos de existência do PNAE, o modelo alimentar dominante do PAE, na maior parte dos municípios e estados brasileiros, 
ainda seguia a lógica da produção em massa, caracterizada por cadeias longas de abastecimento e por concepções de qualidade padronizadas e convencionais, determinando uma relação distante entre consumo e produção.

Dessa forma, mesmo estando abaixo das mesmas legislações dos outros municípios, alguns locais "adaptaram" a estrutura existente, apontando para o fato de que os atores sociais $[3,4]$ e o local [5] são capazes de criar dispositivos para modificar e intervir sobre as estrutura pré-existente, tais como as leis e os mercados. Nesse sentido, parte-se do princípio de que um mercado não é idealizado e planejado a priori, mas construído de forma fragmentada, contingente, combinada, e que as iniciativas locais são precursoras e, conjuntamente, com as posturas do Estado, potencializadoras das mudanças.

A literatura internacional indica que a origem de formas diferenciadas de relações sociais e econômicas que determinam modelos alimentares que fogem ao convencional parte de movimentos que surgem tanto da necessidade de sobrevivência dos pequenos agricultores, quanto, atualmente, das preocupações e concepções de qualidade dos consumidores. Nesse contexto, o reconhecimento da ruptura e da desconexão na cadeia alimentar implicaria o apoio e a ideia da sobrevivência agrícola e da restauração da confiança na produção de alimentos pelo consumidor, por intermédio da construção de cadeias alimentares localizadas ${ }^{[5]}$ pautadas em "economias de qualidade" $[6,7]$ e na sustentabilidade $[8]$.

Embora existam dispositivos alternativos estabelecidos principalmente pela relação e interação dos atores locais, o setor público tem um papel fundamental na definição dos modelos de desenvolvimento e qualidade a serem seguidos. Nesse sentido, o Estado possui um papel fundamental na regulação e orientação da produção agroalimentar via controle e normatização do uso de agroquímicos e, também, da saúde alimentar e nutricional da coletividade, via estímulo ao consumo de alimentos frescos e mais saudáveis. $O$ poder público pode, efetivamente, constituir-se em um ator-chave na construção de formas de produção e consumo de alimentos que primem pela observância das diretrizes da segurança alimentar e nutricional e da produção sustentável.

Nessa perspectiva, estudos recentes têm procurado desenvolver abordagens teóricas mais integradas e holísticas para a produção e consumo. Exemplo disso é o trabalho realizado na Universidade de Cardiff que, dentre outros temas, tem utilizado o school meals para explorar as relações entre estratégias de produção baseadas na qualidade $\mathrm{e}$ as formas de discernimento dos consumidores que procuram alimentos mais confiáveis, ou seja, frescos, locais e de conhecida procedência. No centro dessa temática, está o conceito de aquisições públicas sustentáveis [9], que aponta, entre outros fatores, para o poder de regulação do Estado para a criação de mercados para agricultores locais e para a promoção de saúde e bem-estar, referenciando-o como política de saúde pública. Nesse sentido, Lang e Heasman [10] defendem o conceito de um "paradigma ecológico integrado", mostrando que a saúde e os recursos naturais estão intimamente ligados e que a sustentabilidade está intrinsecamente conectada a ambos.

Neste trabalho, pretende-se apresentar um caso em que está em curso uma reconexão bem sucedida entre agricultores e escolares. Tomando-se o município de Dois Irmãos (RS), pretende-se mostrar como o Programa de Alimentação Escolar foi utilizado para construir novas relações de produção e consumo, promovendo alternativos, diferenciados e/ou heterogêneos modelos agroalimentares; como e por que esse processo ocorreu; quem foram os atores e quais as os potenciais resultados. Dessa forma, pretende-se também refletir sobre uma experiência bem sucedida desse processo no Brasil e apontar as lições que se podem extrair dela, apresentando algumas recomendações. Com isso, busca-se ampliar o reconhecimento da necessidade de mais pesquisas sobre o tema.

\section{Metodologia}

A escolha do estudo de caso justifica-se pela necessidade de aprofundar o conhecimento de uma realidade delimitada, visto a complexidade da problemática, a diversidade, a dinâmica e contingência das relações em diferentes espaços no que diz respeito ao tema tratado.

O motivo de a escolha do caso a ser investigado neste estudo ser o município de Dois Irmãos (RS) devese ao fato de que foi um dos primeiros municípios em nível de País a realizar a compra de produtos da agricultura familiar local para a alimentação escolar, iniciando o processo em 2004. Além de ser um dos pioneiros na implementação do Programa para aquisição de gêneros alimentícios de pequenos produtores, também manteve essa prática de forma constante ao longo do tempo, o que demonstra que houve uma iniciativa que se consolidou e adquiriu autonomia em relação às mudanças dos gestores públicos. 
Em um primeiro momento, para caracterizar o "município-caso" realizou-se um levantamento de dados secundários sobre a região em que ele se insere e sobre ele especificamente. Esses dados secundários foram de duas ordens: (a) dados provenientes de censos e estatísticas (IBGE) e de levantamentos de campo realizados em outras pesquisas ou trabalhos de acompanhamento disponíveis para consulta; e (b) informações sistematizadas na forma de mapas, relatórios técnicos, artigos de pesquisa, diagnósticos, livros. Nessa primeira coleta de dados, buscaram-se não só dados relativos às questões sociodemográficas, mas também às questões mais gerais vinculadas ao Programa de Alimentação Escolar do município e a sua relação com a agricultura local.

Para captar informações sobre as suas atitudes, valores, conhecimentos, opiniões, dos indivíduos foram elaborados roteiros de perguntas para a orientação do diálogo com cada grupo específico de entrevistados. Os roteiros foram aplicados por meio de entrevistas semiestruturadas. Em relação aos gestores, elaboraram-se roteiros diferenciados para os que estavam diretamente envolvidos com a escolha dos alimentos a serem comprados, que, a princípio, corresponde ao Setor de Alimentação Escolar, composto por nutricionista, coordenação, direção e merendeiros, considerando-os também como consumidores.

As entrevistas foram realizadas nos locais onde as pessoas trabalhavam (escolas, prefeitura, propriedade do agricultor, feira) ou em algum lugar escolhido por elas (suas casas, escritório da Emater). Na maioria dos casos, todos se retiravam de suas atividades durante o tempo da entrevista, salvo algumas exceções em que não houve alternativa, senão inquiri-los durante o trabalho. Todos os encontros foram previamente agendados, informando primeiramente o teor da entrevista e o objetivo da pesquisa, e solicitando ao informante o consentimento em participar e garantindo o seu anonimato.

A linguagem nas entrevistas foi conveniente com o público-alvo que, por sua vez, era bem variado em relação à escolaridade, para permitir um bom entendimento das questões, reelaborando-as se necessário.

Em relação ao critério de amostra, buscou-se identificar aquela que fosse capaz de refletir a totalidade nas suas múltiplas dimensões. Para tanto, seguimos os critérios referidos por Minayo [11], quais sejam: definir o(s) grupo(s) social(is) mais relevante(s) para as entrevistas e observação; não se esgotar enquanto não delimitar o quadro empírico de pesquisa; prever um processo de inclusão progressiva encaminhada pelas descobertas de campo e seu confronto com a teoria; e prever uma triangulação.

Para identificar os atores envolvidos no processo de construção dessas cadeias alimentares localizadas por meio da alimentação escolar, foram entrevistados representantes dos seguintes grupos: consumidores, produtores e gestores públicos. Necessário aqui definir o que este estudo entende por consumidor, produtor e gestor e, nesse entendimento, quem foram os atores pesquisados.

Por consumidor, entenderam-se não só os alunos que, de fato, são os que efetivamente fazem uso do bem, mas, principalmente, seus representantes diretos, seus pais. Destacam-se também como consumidores os responsáveis pela escolha do que será adquirido, ou seja, quem define o que deve ou não ser consumido por esses alunos, que, dependendo do município, pode ser o nutricionista que elabora o cardápio ou coordenador do serviço (que muitas vezes não é o nutricionista), ou o diretor e o corpo de funcionários da escola (serventes, merendeiros).

Por produtores caracterizaram-se os agricultores familiares que, enquadrados ou não nos critérios do Programa Nacional de Fortalecimento da Agricultura Familiar (PRONAF) ${ }^{4}$, sejam pequenas unidades de produção de caráter familiar. No entanto, partindo do princípio de que não há apenas uma forma de ser das familias, mas sim uma significativa diversidade social, e que, na realidade, o estudo da agricultura familiar requer uma análise sociológica multidimensional para defini-la [12], evitar-se-á simplificações considerando essa premissa. Os agricultores familiares a serem considerados na pesquisa foram os que fornecem ou forneceram gêneros para a alimentação escolar. Consideraram-se também as entidades representantes dos produtores, a exemplo dos Sindicatos dos Trabalhadores Rurais, Extensão Rural (Emater), Associações e Cooperativas de agricultores.

Os gestores são entendidos aqui como os responsáveis pelas atividades de planejamento, organização, liderança e controle de uma organização, no caso, pública. Assim, gestores municipais como prefeito, secretários de educação e agricultura, setor de

\footnotetext{
4 O Programa Nacional de Fortalecimento da Agricultura Familiar (PRONAF) destina-se ao apoio financeiro das atividades agropecuárias e não agropecuárias exploradas mediante emprego direto da força de trabalho do produtor rural e de sua família e, para tanto, apoia-se em um enquadramento desses produtores rurais , de acordo com características de renda, residência, exploração da terra, força de trabalho, grupos específicos, comprovados mediante Declaração de Aptidão ao Programa (DAP).
} 
alimentação escolar, vigilância sanitária e outros departamentos da secretaria de saúde que exerciam, ou estavam exercendo, algum poder de decisão e gerência desse serviço, foram entrevistados.

Nesse sentido, é importante destacar o estudo das entidades que reúnem esses atores, como os Conselhos de Alimentação Escolar e de Desenvolvimento Rural, já que são potenciais locais de discussão e troca entre produtores e consumidores, Estado e sociedade civil. Para tanto, foram utilizadas para a análise todas as atas registradas desde a criação de cada Conselho.

A análise dos dados qualitativos foi realizada pela categorização temática. Para isso, utilizou-se o referencial sobre análise de conteúdo. Para efetuar a sistematização e a análise dos dados coletados a partir das respostas das entrevistas, documentos e observações levadas a efeito, foi utilizado o software NVivo 2. De acordo com Guizzo et al. [13], esse software é útil na administração e na síntese das ideias do pesquisador, permitindo que se realizem mudanças nos documentos com que se está trabalhando, sendo possível acrescentar, modificar, ligar e cruzar dados ou, ainda, registrar ideias. Assim, ele tem a capacidade de organizar e analisar os dados de uma forma operacional, sistemática e efetiva, facilitando a operacionalização de uma grande quantidade e diversidade de informações.

\section{Resultados e Discussão: a construção social de um novo mercado para a agricultura familiar a partir do Programa de Alimentação Escolar em Dois Irmãos (RS)}

O município de Dois Irmãos integra a Região Metropolitana de Porto Alegre, e está localizado a apenas $52 \mathrm{~km}$ da capital na região nordeste do Estado do Rio Grande do Sul. Possui uma população de 24.815 habitantes, uma área de $65,16 \mathrm{~km}^{2}$ com uma densidade populacional de $380,9 \mathrm{hab} . / \mathrm{km}^{2}$, sendo o $7 .^{\circ}$ município mais urbanizado do Estado no ano de 2000 (IBGE, 2007). O PIB per capita em 2007 foi de R $\$ 16.664,00$ (IBGE, 2007) e o Índice de Desenvolvimento Humano (IDH), segundo PNUD 2000, de 0,812.

Sua história está ligada à colonização alemã no Estado, a qual teve início no ano de 1824 na antiga Colônia de São Leopoldo. Os imigrantes vindos diretamente da Europa afirmaram-se sobre a agricultura, $\mathrm{o}$ artesanato rural e o comércio, sendo o comércio rural o principal mecanismo de contato com os imigrantes das colônias com a sociedade gaúcha [14]. Dois Irmãos recebeu os primeiros colonos a partir de 1825 , e teve sua ocupação basicamente por intermédio da atividade agrícola desenvolvida nos lotes que se alinharam lado a lado, no sentido norte-sul. Essa forma de ocupação geográfica associada à etnia, ao domínio da língua germânica e às dificuldades de comunicação foram fatores decisivos à formação e manutenção de uma sociedade endogâmica e, relativamente, fechada sobre si mesma até meados da década de 1950, quando foi desarticulada por um duplo processo de transformação estrutural da economia do Estado. Por um lado, as mudanças ocorridas na agricultura familiar e, por outro, em razão do processo de industrialização difusa do setor coureiro-calçadista ${ }^{[14]}$.

Isso permitiu ao colono reestruturar a divisão interna do trabalho familiar e adequar a unidade agrícola ao mercado de trabalho não agrícola. Dessa forma, constitui-se uma mudança na estrutura produtiva da agricultura familiar, que passa de um modelo colonial fortemente assentado na produção para autoconsumo e venda de excedentes para uma atividade integrada aos mercados, caracterizada pelo deslocamento diário e pendular de membros das famílias para o trabalho nas indústrias de calçados [15].

Essa mudança fez com que o processo de urbanização do município e da região como um todo se acelerasse, e atualmente Dois Irmãos tem uma área rural que corresponde a cerca de $10 \%$ da sua área total. Segundo dados da Emater local, o meio rural ainda se caracteriza pela presença de pequenas propriedades de agricultores familiares, destacando-se o cultivo de mandioca, feijão, olerícolas, milho, além da criação de bovinos de leite, bovinos de corte, cabras, peixes, produção de ovos, mel, e agroindustrializados (néctar e doces de frutas, doces de leite e ovos, queijo de cabra, leite). Esses produtos são comercializados em sua maior parte no mercado local e regional e, também, para autoconsumo. Segundo o Censo Agropecuário de 2006, o número de estabelecimentos agropecuários era de 127, ocupando uma área de 1.727 hectares, distribuídos entre as áreas rural, urbana e rurbana ${ }^{5}$.

\section{Das origens e motivações para mudança no abastecimento}

O PAE era abastecido com gêneros alimentícios adquiridos pela instância federal que os distribuíam para todo país até 1994, quando inicia o processo de

\footnotetext{
${ }^{5}$ Esta classificação é dada pelo Plano Diretor do Município (Lei no 2.375/2006) que estabelece os critérios para o macrozoneamento. Convém ressaltar que os agricultores que estão na zona considerada urbana, mas que comprovem a sua utilização para fins de produção agrícola são classificados como contribuintes do ITR e não IPTU.
} 
descentralização, em que o recurso é repassado para os municípios que assumem a aquisição dos produtos. Até então, eles eram industrializados (em sua grande maioria formulados), não faziam parte do hábito alimentar local e, muitas vezes, chegavam ao município sem condições para consumo. Mesmo com a melhora nesses aspectos, depois que o gerenciamento passou a ser do município, a aquisição continuou sendo realizada de mercados varejistas ou atacadistas.

Para entender o que se passou no município de Dois Irmãos e explicar seu turning point pode-se utilizar da pergunta de Norman Long [4]: por que em situações similares e circunstâncias históricas parecidas, indivíduos ou grupos sociais fazem escolhas diferentes? O que explica o fato de Dois Irmãos, um município tão semelhante aos demais da região de seu entorno, optar por uma mudança decisiva em seu Programa de Alimentação Escolar? A partir dessas indagações é que se procuraram identificar as motivações que deram origem à mudança relativa ao abastecimento, ou seja, por que comprar os produtos de agricultores familiares?

Segundo depoimentos da Coordenação do Programa de Alimentação Escolar de Dois Irmãos, o município cria o Conselho de Alimentação Escolar (CAE) em 1995, exigência legal para poder receber os recursos e assumir a gestão do Programa. Segue-se que, depois da descentralização, iniciaram as discussões sobre a qualidade dos alimentos de forma mais intensa, em virtude da baixa aceitabilidade e aproveitamento dos gêneros adquiridos, agora, por causa das limitações do processo licitatório.

Essa precariedade da qualidade do produto somou-se ao diagnóstico preocupante do estado nutricional dos alunos da rede municipal. Em 2003-2004, foram realizadas pesquisas, demonstrando um quadro alimentar e nutricional que atestava a tendência nutricional observada no País: o aumento dos índices de sobrepeso associados a práticas alimentares caracterizadas pelo consumo de alimentos com alta densidade energética e industrializados em detrimento dos básicos e mais naturais. A pesquisa realizada nos municípios de Dois Irmãos e Morro Reuter com escolares de oito a dez anos ${ }^{[16]}$, verificou que $17 \%$ estava acima do peso, que a obesidade estava fortemente associada a práticas alimentares menos saudáveis e que os conhecimentos sobre nutrição não eram suficientes para que essas crianças se conscientizassem e melhorassem suas práticas. Essas constatações levaram a concluir que o ambiente é decisivo na formação de hábitos alimentares e fundamental para modificar a alimentação e prevenir doenças. Foi com essa concepção que o PAE desse município começou a trabalhar na revisão das questões de qualidade dos alimentos, remetendo esse conceito às questões organolépticas e culturais, associadas às questões nutricionais e sanitárias. Disso resultaram as motivações para repensar a procedência e métodos de produção que providenciassem alimentos mais frescos, naturais, tradicionais e saborosos, que conquistassem o paladar dos alunos para alimentos como frutas, verduras e gêneros menos processados, integrais e típicos da região.

Deve-se frisar que essas preocupações acentuaram-se em discussões sobre a aquisição de alimentos da agricultura familiar a partir do movimento iniciado em nível regional para a inserção de produtos desse tipo de agricultura no Programa ${ }^{6}$. O município foi participante desse movimento que vinha de encontro às necessidades suprarreferidas. Segundo Emater e o Sindicato dos Trabalhadores Rurais (STR), havia também o interesse de procurar alternativas de mercado para a agricultura familiar, porém isso não teria sido o motivo primeiro, mas sim uma motivação que se unia e vinha ao encontro da proposta. O interesse dos agricultores pela alimentação escolar, segundo eles, não foi somente pela segurança e solidez que esse mercado providenciava, mas também por ser um vetor de comércio local.

Para tal, as entidades citadas como responsáveis pelo movimento no município foram à Secretaria de Educação, por intermédio da Coordenação da Alimentação Escolar, STR e a Emater, envolvendo, após, vários outros atores, como os serventes de escola, os professores, os diretores, os pais de alunos, os agricultores, a Secretaria da Saúde por meio da Vigilância Sanitária e o Departamento da Agricultura. Os encontros e discussões sobre o assunto entre esses atores tomavam acento principalmente dentro do Conselho de Alimentação Escolar e, com menor intensidade, no Conselho de Desenvolvimento Rural. Essas entidades reuniram esforços para incentivar, ajudar e mobilizar os

\footnotetext{
${ }^{6}$ Entidades como a Emater e a Federação dos Trabalhadores na Agricultura (FETAG), na tentativa de criar mercados para a agricultura familiar, bem como promover desenvolvimento local e soberania alimentar [17] foram responsáveis por um movimento regional iniciado em 1998, no município de Rolante (RS). Em 1999, essa iniciativa produziu repercussão em outros municípios, culminando em 2004, no Seminário Regional sobre Alimentação Escolar. Neste, participaram 15 municípios, representados por Secretários Municipais, técnicos, integrantes de conselhos municipais, agricultores, merendeiros, professores e diretores de escolas, que discutiram amplamente a questão de aquisição de produtos locais para o abastecimento das escolas. Desse encontro, criou-se uma comissão multidisciplinar, interinstitucional e intermunicipal, com objetivo de dar suporte técnico e estratégico aos municípios, além de divulgar o tema para outras regiões do Estado e do País. Para tal função, a comissão elabora e lança, em 2005, o Manual de Alimentação Escolar, atualizado e relançado em 2006, frisando a latência do mercado institucional como demandante de produtos da agricultura familiar.
} 
agricultores, visitando-os ou convidando-os para participarem das licitações.

Em 2004, efetivou-se essa prática, com o início da participação de produtores rurais nos processos licitatórios. Desde então, já participaram direta e indiretamente como fornecedores, mais de vinte agricultores que produzem leite integral pasteurizado tipo C, néctar de uva orgânico, geleia e doces em pasta de frutas orgânicas, doce de leite, ovos de galinha caipira e de codorna, mel em pote e sachê, hortaliças e frutas. Abastecem, dessa forma, toda rede municipal de ensino, constituída por onze escolas municipais, o que representa em torno de 3.500 alunos. Considerando o ano de 2009, o município recebeu o montante de $\mathrm{R} \$ 151.591,35$ do governo federal para o PAE. Desses, $\mathrm{R} \$ 89.068,69$ foram utilizados para compra de alimentos da agricultura familiar, ou seja, praticamente $60 \%$ do total do recurso federal.

\section{As dificuldades e as estratégias de superação}

Como visto acima, as motivações, necessidades e interesses dos atores envolvidos levaram-nos a repensar o modelo e, para isso, determinadas dificuldades tiveram de ser superadas. Três delas destacam-se nos depoimentos: (1) burocracia do processo licitatório; (2) formalizações dos produtores em relação, principalmente, às questões sanitárias; e (3) organização da produção, comercialização e logística.

Para que houvesse a superação de dificuldades, foi necessário utilizar-se de estratégias. Um enfoque orientado ao ator emprega-se com a simples ideia de que, nas mesmas ou similares circunstâncias estruturais, desenvolvam-se formas socialmente diferentes. Tais diferenças refletem variações nas maneiras em que os atores intentam encarar ou lidar cognitiva, organizacional e emocionalmente com as situações. Assim, a ação estratégica caracterizar-se-ia por um poder que os atores têm de, mesmo dentro de um modelo cultural ou social dominante, serem agentes hábeis em mudar as circunstâncias para resolver seus problemas de uma forma coerente, organizando seus recursos por meio de uma persuasão ativa em relação aos seus projetos e pela construção de seus próprios padrões de organização [4].

\section{Processo licitatório}

Todos os recursos utilizados em compras públicas, inclusive os remetidos à alimentação escolar, obrigatoriamente até 2009, deveriam ser licitados ${ }^{7}$. Para

\footnotetext{
${ }^{7}$ A dispensa licitatória pode dar-se em algumas situações emergenciais ou em objetos que não ultrapassem o montante de $\mathrm{R} \$ 8.000,00 /$ ano, e mais
}

isso, a Entidade Executora municipal realizava pelo menos dois processos licitatórios por ano na modalidade Pregão Presencial ou Eletrônico, e, para compras emergenciais, Convite ou Dispensa de Licitação.

A questão da burocracia das aquisições públicas foi enfrentada a partir de intensas discussões no CAE. O encontro de diversos atores representando tanto os consumidores (professores, pais e Coordenação do Serviço), quanto os produtores (Sindicato dos Trabalhadores Rurais, Emater), além de outros convidados, como a Vigilância Sanitária, Secretarias da Agricultura e da Saúde, resultaram na formulação de estratégias capazes de contornar os problemas burocráticos. Por meio dessas aproximações, ocorreu a reformulação dos cardápios e das especificações dos produtos conforme o que e quanto era produzido pelos produtores rurais do local, e o auxílio na adequação aos mesmos quanto aos documentos necessários para sua participação dos processos licitatórios. Relativamente à documentação, houve uma adaptação das exigências da Lei 8.666/1993, formulada em conjunto com o Departamento de Compras e Departamento Jurídico. Para que os agricultores pudessem participar do certame, tinham de apresentar o Cadastro de Pessoa Física (CPF) e o bloco do Produtor Rural, além de negativas de débito das diferentes esferas estatais, considerando-os como documentos símiles aos exigido às Pessoas Jurídicas.

No entanto, segundo depoimentos da Coordenação do PAE, mesmo com esse auxílio, a manutenção do vínculo era dificultada pela própria Lei de Licitações e suas prerrogativas. Dessas, frisa-se a livre concorrência e a isonomia, que ditam o dever de selecionar a proposta mais vantajosa para a Administração, vetando-se aos agentes públicos agir de forma a frustrarem ou restringirem o seu caráter competitivo. Decorrente disso, ao participarem desse processo, os agricultores familiares faziam-no, competindo com outros fornecedores, como atacadistas e varejistas. Ao contrário do que se pensa, nem sempre seus preços eram competitivos. Primeiro, porque seus

recentemente, em função da Lei 11.947 de 16/06/2009. Frisa-se que, na tentativa de ultrapassar a burocracia dos processos licitatórios, muitos municípios utilizavam o Programa de Aquisição de Alimentos (PAA) do Governo Federal, instituído em 2003, justamente com o objetivo de desburocratizar a compra de produtos da agricultura familiar. No entanto, o recurso utilizado não seria o relativo à alimentação escolar, mas, sim, do próprio PAA, que adquiriria de agricultores familiares para posterior doação para complementar a alimentação de públicos vulneráveis, dentre os quais a das escolas e creches. Nessa construção, o PAA destacou ainda mais o grande potencial do Programa de Alimentação Escolar em concretizar as políticas de segurança alimentar vinculando consumo e produção. O PAA foi um programa que revelou potencialidades nas compras públicas de alimentos para públicos vulneráveis, e esse foi um "laboratório" em relação à mesma prática a ser realizada pelo PAE, o que acabou fortalecendo a criação da Lei 11.947 de 16/06/09. 
concorrentes muitas vezes cotavam um produto de qualidade inferior (principalmente frutas e verduras) e, segundo, porque sua produção de baixa escala tornava-se onerosa, quando feitas exigências estruturais e logísticas.

Para suplantar essas questões, as especificações dos produtos nos Editais passaram a ser mais detalhadas, além de virem com exigências de qualidade referindo características de produção e manipulação diferenciadas que condiziam com o que e como eram os alimentos produzidos na região. Por exemplo, o leite produzido no município distingue-se dos demais leites pasteurizados tipo C pela característica da manutenção da gordura (tipo "integral"), sem a sua padronização a 3\% (tipo "padronizado"), como é a maioria dos oferecidos no comércio. Esses gêneros passavam também pelo Núcleo de Controle de Qualidade, que atentava para o atendimento estrito às exigências do Edital, podendo desclassificar as propostas que não estavam de acordo com o padrão de qualidade descritos. Assim, o proponente deveria, além de oferecer o menor preço, também comprovar a qualidade exigida no certame para fornecer determinado gênero alimentício ao PAE.

Nesse exemplo, observa-se que, ao transformar os mercados institucionais em potenciais vetores de saúde pública e de desenvolvimento sustentável, passa-se a vê-los como possíveis novos nichos de comercialização de produtos da agricultura familiar local. Porém, a primeira barreira encontrada para sua efetivação é o fato de que as legislações das compras públicas não são adequadas a esse propósito. Morgan ${ }^{[8]}$ defende que a reforma mais importante que deve ser criada para um novo conjunto de práticas é um quadro regulatório de incentivos e sanções globais e locais que promovam, e não frustrem, a ampliação de cadeias alimentares sustentáveis. Para ele, fazendo-se uma análise da União Européia, a maior barreira para essas cadeias assentam-se no "formidável arcano das normas das compras públicas". No Reino Unido, por exemplo, compras que especifiquem adjetivos como "local" são consideradas ilegais por ferirem os princípios da livre concorrência, como a transparência e a não discriminação. Por outro lado, países como França e a Itália seriam mais criativos em relação à interpretação das regras, ao especificar certas "qualidades" nos produtos a serem comprados, caracterizando-os como "orgânicos", "sazonais", "frescos", incentivando dessa forma as cadeias locais de abastecimento. Morgan e Morley ${ }^{[18]}$ constatam que, no Reino Unido, o ponto-chave para essa interpretação diferenciada dos demais países é a cultura da "aversão ao risco", o que liga diretamente a uma zona obscura entre legalidade e ilegalidade, quando se tenta fazer algo novo ou inovador. Assim, mais do que promover cadeias sustentáveis, preferem permanecer na zona de conforto de costumes e práticas.

\section{Questões de qualidade}

Outra dificuldade enfrentada na aquisição de alimentos da agricultura familiar para o PAE foi o atendimento às exigências relacionadas aos padrões de qualidade dos produtos agroindustrializados. Mais especificamente, aos relacionados às questões sanitárias e às formalidades exigidas para sua comprovação, como os Registros de Inspeção, Registros nos Ministérios concernentes (dependendo do produto), cadastros e alvarás do estabelecimento, entre outros. Segundo os próprios agricultores e o STR, essas exigências, impossibilitavam a sua formalização devido à necessidade de tomarem uma série de medidas que exonerariam a produção a ponto de eles não conseguirem adequar-se.

Outra questão foi a sanitária. Foi e ainda é um grande problema dentro da estrutura minima exigida. Eles (agricultores) têm medo de investir porque não têm certeza do sucesso, eles têm muito receio de cumprir todas as exigências sanitárias e não ter retorno. Foi o único motivo que prejudicou. Mesmo que o municipio tente facilitar, não dá. Acho que a fiscalização deveria acompanhar com a estrutura que se tem e no decorrer que ela vá exigindo a adequação necessária. Inverter um pouco a lógica (P. J. B., STR).

Para a superação desse entrave, o município contou com ações conjuntas entre a Secretaria de Saúde e Agricultura para a implementação do Serviço de Inspeção Municipal (SIM), que promoveria um maior número de produtores aptos, do ponto de vista sanitário, a venderem seus produtos para a Merenda Escolar do município. Em 2006, foi criada a Lei no 2.315, regulando a inspeção industrial e sanitária de produtos de origem animal. Até então, somente dois produtores de leite possuíam o SIM, inspecionados por profissionais veterinários da própria Prefeitura, muito embora não existisse ainda a regulamentação legal, e, segundo os entrevistados, esse Serviço não foi eficiente e rápido o suficiente para atender à demanda. Dessa forma, foi necessário fortalecer a parceria entre os diferentes técnicos e instituições envolvidos, desencadeando uma relação de confiança sem exigências de rótulos, etiquetas ou certificados. Essa confiança era baseada no conhecimento do processo de produção dos alimentos pelos técnicos da prefeitura e Emater, criando outros mecanismos para superação das questões de documentação e inspeções sanitárias como, por exemplo, segundo o técnico da Emater,

Em relação à documentação, o termo para a superação é "arranjo". O "arranjo" foi feito pela confiança do produto 
elaborado e essa confiança é dada pelas instituições de base, Sindicato, Emater, Secretaria de Agricultura e pelo histórico dos produtores e os resultados que ele obteve. Existe essa confiança, seus produtos não vão ocasionar mal à saúde de ninguém. Depois, por parte do pessoal da nutrição em entender que isso é importante. Que os alimentos têm um diferencial positivo. (H. M. B., Emater)

Esse esforço parece estar centrado na busca de uma "qualidade" alimentar além dos padrões estabelecidos. Uma qualidade baseada em relações de confiança, no conhecimento sobre quem e como produz, no maior comprometimento do produtor e na maior exigência do consumidor que a localização propicia. Comprometimento esse associado à necessidade da manutenção e aumento do mercado pela credibilidade de quem produz e pela exigência associada à satisfação dos interesses relacionados à saúde de quem consome, corroborados nos depoimentos abaixo.

Na fala em relação ao consumo:

Sim, eu tenho muito confiança. Pela qualidade que vem até nós, até o produto chegar na escola, alguém já foi olhar, experimentar, investigar, que a pessoa responsável que comprou tem confiança antes de nós. A gente teria confiança mesmo sem este intermediário, porque é um produto de qualidade. A gente usa no dia-a dia, experimenta, a gente sabe como é, a gente conhece e lida com ele todo dia. Já comprei do Falkoski (agricultor/fornecedor), faço propaganda. Eles são bem falados no município. Nunca foi encontrado um ovo estragado, são bem selecionados (L. K. $M, V$. K., R. I. B., merendeiras).

Não é artificial, não tem agrotóxico, até no cheiro, a gente sente no gosto, quando come é diferente. A gente tem confiança, porque a gente faz. certo então a gente confia que os outros também vão fazere. (L. K. M, V. K., R. I. B., merendeiras).

$\mathrm{Na}$ fala em relação à produção:

[...] são produridos especialmente para um consumidor (escolares) e por isso destinam (os agricultores) a eles (alunos) o que tem de melhor na propriedade. Para permanecer neste mercado, porque eles valorizam este mercado. Eles têm receio de perdê-lo porque ele é aberto, todo mundo pode concorrer contigo. (P. J. B., STR).

Nesse exemplo, pode-se destacar dois aspectos para uma análise mais acurada. O primeiro é que uma nova forma de confiança é constituída nessas relações, que não se baseiam em critérios estabelecidos fora daquela realidade nem em rótulos, marcas, certificados, mas, sim, em uma garantia com rosto, dada por contatos e conhecimentos feitos por trocas voluntárias e sob determinadas condições e valores sociais. Segundo Goodman [7, esse seria um deslocamento da lógica de "produção em massa", em que a qualidade dos alimentos é padronizada e convencional para a "produção doméstica", em que a qualidade está centrada na confiança, na tradição e no local. Essa nova lógica estaria associada a produtos e formas de organização econômica diferenciadas, localizadas e ecológicas. O segundo seria a troca de conhecimentos e negociação. Para Amin e Cohendet [19], as inovações e o conhecimento são gerados por meio de uma combinação de práticas, deliberadas ou não, de compromissos sociais. Os autores argumentam que as comunidades (não necessariamente locais) são responsáveis por gerar aprendizagens estratégicas mediante práticas de socialização, interação, alinhamento de interesses, transmissão de conhecimento, entre outros aspectos. Os espaços de proximidade seriam capazes de potencializar os processos de inovação e aprendizado pela maior circulação de idéias, conhecimentos e experiências compartilhadas, ultrapassando a limitação da regra (do cumprimento da regulamentação sanitária), mas não deixando de cumpri-la com responsabilidade. Por outro lado, constroem novas concepções de qualidade que falam da procedência, da forma de produzir, da "naturalização" do produto, das questões organolépticas e nutritivas.

\section{Organização da produção}

Além da confiança em relação à qualidade do produto do agricultor familiar, o gestor também precisava confiar que o PAE seria abastecido nas quantidades necessárias para cumprir com seu compromisso de oferecer alimentação aos escolares em todos os dias letivos. Para tanto, segundo os depoimentos da Emater e STR, os agricultores precisaram adaptar-se e organizar-se para essa nova lógica de mercado.

A maior dificuldade foi mostrar ao agricultor que era possivel vender para o Programa. Ele não estava preparado para uma produção maior, com mais tecnologia, e que tinha que avançar na questão da qualidade. Por essa dificuldade de ele mesmo ter que enfrentar o mercado, o consumidor mais exigente. Teve que passar a lidar com aquilo que até então não faria. Teve que sair de um papel mais de paternalismo para um papel mais autônomo. Outro problema foi o conbecimento do Programa, fazer a entrega em vários lugares, a questão da logística, principalmente na questão das bortalicas. Tem que saber se organizar, gerenciar sua própria propriedade. Antes eles vendiam o excedente, agora eles têm que mandar o que precisa. Eles são obrigados a levar, têm pessoas dependendo daquele produto. A agricultura não é uma indüstria, ela precisa de seu tempo. Para produrir tantos pés de alface, não adianta ficar enchendo de adubo, ela tem que ter seu tempo. Então eles têm que ser bem organizados. É um avanço como forma de aprendizado (P.J. B., STR). 
Assim, com o auxílio das instituições e com a adaptação ao processo com o tempo, os agricultores conseguiram ajustar-se, como segue o exemplo da produção de leite citada pelo extensionista e confirmada pelo produtor:

Como o leite, aumentou a quantidade. Eles se preparam para esse mercado não deixando a vaca parir no verão, controlando a lactação, a inseminação, já que no verão não bá aulas e diminui a demanda (H. M. B., Emater).

Nesse contexto, torna-se premente a geração de novos conhecimentos sobre processos produtivos e organizativos, tanto no âmbito das unidades de produção quanto entre elas. Nesse processo, o conhecimento dos agricultores (farmers knowledge) torna-se uma questãochave, como pode ser observado nas palavras de Stuiver et al. [20], que diz que deve-se reexaminar o conhecimento dos agricultores em vista da natureza adaptativa dos diversos estilos de agricultura. Para os autores, entender sua lógica subjacente e sua racionalidade é importante porque tem um relevante papel na construção de inovações na agricultura. $\mathrm{O}$ caso em estudo salienta que o conhecimento dos agricultores é implícito à prática produtiva, ou seja, é ancorado na ação. No curso do tempo, os agricultores monitoram, avaliam e ajustam a eficiência de suas práticas e decisões. O ajustamento é constante e leva a novos ajustes nos diferentes domínios da produção. Este ajustamento é uma espiral: agricultores constantemente ajustam, monitoram, avaliam e ajustam novamente. Neste caminho eles aprendem fazendo e fazem através da aprendizagem [20]. Para os autores, essa necessidade de integrar um amplo conjunto de domínios e fatores de influência sobre a prática produtiva torna a experimentação feita pelos agricultores composta por um conjunto muito maior de referências e de parâmetros de análise.

\section{Da governança: o papel do Conselho de Alimentação Escolar}

Segundo Long [3], a coalizão de atores que, pelo menos em um momento dado compartilham alguma definição de uma situação ou metas similares, interesses e valores e que tácita ou explicitamente acordam em perseguir certos cursos de ação social, permite ordenar e sistematizar a experiência, tomar decisões e atuar em consequência. Para o mesmo autor, os atores coletivos podem ser constituídos de maneira informal ou formal e organizados de modo espontâneo ou estratégico.

Importante destacar que o conceito de governança aqui referido vem salientar a existência de um mecanismo mais amplo do que aquele explícito no conceito de governo que se limita às instituições formais e estruturadas do Estado. A governança diz respeito às formas em que organizações governamentais e não governamentais trabalham juntas e como o poder político e a autoridade são distribuídos, interna e externamente ao Estado [21].

Pode-se verificar nesse caso, um exemplo em que a governança se concretiza a partir da concatenação entre sociedade civil e poder público dentro de um Conselho Gestor, no caso, o CAE. Essa foi uma das entidades mais citadas nas entrevistas como local de encontro para discutir os problemas referentes à alimentação escolar, traçar estratégias e providenciar negociações. Por sua vez, desde sua criação, o CAE passou por algumas modificações em sua constituição, sendo atualmente composto (conforme Resolução no 38/2009 do FNDE/PNAE) pelos seguintes representantes com respectivos suplentes: um representante do Poder Executivo, dois dos professores, dois dos pais de alunos e dois da sociedade civil.

Mesmo tendo sua conformação regida por lei federal, partiu do governo municipal o interesse em trabalhar conjuntamente com representantes da sociedade que fossem estratégicos na implementação dessa prática. Desses representantes, destaca-se que participam atualmente do CAE municipal entidades como o STR, a Emater, Associação dos Cunicultores, Vigilância Sanitária e Secretaria da Educação.

A partir das atas de reuniões e dos depoimentos dos entrevistados, verifica-se a mobilização e comprometimento desses atores nas discussões e tratativas referentes às questões da alimentação escolar e ao seu amparo junto ao poder público. Segundo depoimento de um dos Conselheiros:

[...] as idéias são ouvidas, não são como em outros lugares que as decisões são de gabinete e o Conselho serve apenas para constar, fazer uma "reuniãozinha". Me envolvi de corpo e alma dentro do CAE. Desde que entrei no Sindicato praticamente participo do CAE. Gosto de poder contribuir, a gente sente que pode ser útil (P. J. B., STR).

A agência, implicando a geração e uso ou manipulação de redes de relações sociais e a canalização de elementos específicos por meio de pontos nodais de interpretação e interação, explicita como os atores sociais comprometem-se e são envolvidos nos debates acerca da atribuição de significados sociais aos eventos particulares, ações e idéias. Com esta disposição da sociedade civil e do poder público, foi que o processo de compras de alimentos de agricultores familiares começou a ser 
discutido e implementado conforme depoimentos abaixo:

Acho que o CAE tomon a frente, chamava os outros segmentos, ia atrás, via o interesse dos outros, promoveu encontros. Dentro do CAE procurei opinar, questionar, participar de tudo que era proposto neste sentido. Eu achava que era muito positivo e tinha muito para dar certo (I. C. B. B., mãe de aluno).

[...] o responsável pelo movimento foi um conjunto de entidades que se uniram e que formavam o CAE. Tinham uma idéia semelhante (P. J. B., STR).

Verifica-se nos depoimentos que os envolvidos concordam quanto à questão da necessidade da união de forças e do trabalho conjunto na busca de um objetivo comum. Segundo o técnico da Emater "o mais importante de tudo era a existência de uma consciência coletiva de onde se queria chegar. As acões e as adequacõos efetuadas visavam um objetivo comum". Remete-se à importância de um acompanhamento contínuo, da vontade política, da sensibilidade e da conscientização dos atores sociais e de concepções de qualidade diferenciadas, tendo em vista a grande dificuldade em manter o vínculo nos termos regulatórios e burocráticos existentes. Convém destacar também, que os atores sentiam-se fazendo parte do processo de alguma forma; eram em parte "donos" do projeto, porque, de algum modo, ele vinha ao encontro de seus interesses, de suas necessidades ou de suas motivações, e contribuía para fortalecer vínculos, motivando-os e valorizando-os, ou seja, havia articulação de projetos, interesses e perspectivas de outros atores, o que vai de encontro às interações de interface que pressupõem algum grau de interesse comum, mas que também têm uma propensão para a geração de conflito devido aos interesses contraditórios e objetivos ou das relações de poder desiguais.

Assim, embora houvesse a vontade dos atores envolvidos, existiam normas e instituições, como visto acima, que barravam as ações. Para a criação de um espaço de manobra, era necessário um grau de consentimento, de negociação, e, desse modo, um grau de poder, manifestado na possibilidade de exercer algum controle, prerrogativa, autoridade e capacidade para a ação, seja em primeiro plano ou nos bastidores, em momentos flutuantes ou em períodos mais sustentados [4].

Isso pode ser exemplificado a partir das questões sanitárias, em que os conhecimentos e domínios dos expertos foram debatidos junto ao CAE, conforme frisa a mãe de aluno que participava desse Conselho, na passagem a seguir transcrita:
Muito positivo foi o encontro em que várias pessoas, veterinários, Vigilância Sanitária e o SIM juntos tentaram ver uma forma de ajudar a vencer esta barreira. Isto aconteceu no CAE, numa reunião. Fora isso a Emater promovia encontros, os veterinários iam até os locais e prestavam esclarecimentos, sempre se mostrando prontos quando o agricultor mostrava interesse em participar. E mostravam os caminhos, e apontavam o caminho. (I. C. B. B., mãe de aluno).

Portanto, o CAE servia como uma importante arena em que transcorriam contendas e discussões sobre assuntos, recursos, valores e representações. Nas palavras de Long [4], o CAE pode ser entendido como um sítio social e espacial em que os atores se confrontam para alcançar fins específicos, inclusive, permanecer no jogo. É nesse sentido que o CAE se caracterizava como local onde se buscavam resolver discrepâncias nas interpretações de valor e incompatibilidades entre os diversos interesses.

Para Long [4], o importante nessas estratégias é que as decisões ou o posicionamento social frente a outros atores implicam o uso explícito ou implícito de meios discursivos, seja na formação de metas, perseguição de interesses, cumprimento de desejos, seja na apresentação de argumentos ou racionalizações para as ações empreendidas. Esses meios discursivos ou tipos de discursos variam, não só entre os atores, mas também são parte de bagagens diferenciadas de conhecimento e recursos disponíveis de atores de diferentes tipos.

Salienta-se que o CAE não só foi responsável pelo aconselhamento junto ao poder público local, mas também foi procurado por outros municípios, e, mais que isso, foi visitado e ouvido por representantes da esfera federal em relação à prática da aquisição de alimentos dos agricultores familiares, lutando pela mudança institucional do processo:

[...] me recordo da época que participei do Conselho que a gente discutia isso, vinham pessoas de fora, $e$ a gente apresentava a vontade que a gente tinha em relação a isso para as pessoas que vinham de Brasilia. Tinha esse interesse, mas que para a parte legal era dificicil. A gente pedia ajuda, explicação, apoio para estas pessoas que vinham de Brasilia. E muito nas capacitaçoes, também se discutia. Também tinha o interesse de outros municípios (I. C. B. B., mãe de aluno).

Em 2005, essas ações foram agraciadas com o Prêmio Gestor Eficiente da Merenda Escolar na categoria Continuidade, promovido pela ONG Fome Zero em parceria com o Ministério da Educação, atestando a aprovação do Governo Federal não só da iniciativa, mas também da sua persistência. 
Assim, assume-se que os modelos diferenciados que aparecem são em parte, criação coletiva dos atores mesmos. Giddens [22] pontua que as ações particulares constituem e reconstituem as condições institucionais de ação dos outros, tal como as ações dos outros o fazem com as particulares. Atividades particulares, então, são incrustadas e são elementos constitutivos de propriedades estruturadas de instituições que se estendem além do seu espaço e tempo.

\section{Das contribuições desta política à produção e ao consumo de alimentos}

Partindo dessa experiência que conseguiu suplantar as barreiras e efetivar as compras para a alimentação escolar de agricultores familiares, destacamse alguns potenciais resultados e as contribuições desse processo no que diz respeito ao consumo e à produção de alimentos.

Ao considerar que o perfil alimentar e nutricional brasileiro complexifica-se a partir da década de 1980, e que muito dessa configuração é consequência de uma forma de produção cada vez mais industrializada e globalizada, a alimentação escolar passa a ter um papel importante na remodelação desses aspectos. No Brasil, o PAE tem seguido, predominantemente, essa forma de regulação, oferecendo alimentos processados, adquiridos de médios a grandes produtores e comerciantes, incentivando, em última instância, a construção de um mercado consumidor para esse tipo de alimento. Somado a isso, considera-se ainda, a influência da mídia e das estratégias de consumo da indústria e o frágil enraizamento cultural alimentar, como pontos fulcrais de perpetuação do modelo agroalimentar dominante. Convém considerar, nessa argumentação, que é na infância que mais facilmente estabelecem-se os hábitos alimentares que, peremptoriamente, perdurarão na adultícia. Dessa forma, o PAE, sendo um dos programas de assistência alimentar que atinge o maior número de pessoas (principalmente crianças e adolescentes) e que, em muitos casos, é a única refeição com qualidade nutricional do dia, deve ser considerado como possibilidade real na construção de uma cadeia alimentar diferenciada.

Nesse sentido, a efetivação da compra de alimentos para a "merenda escolar" de agricultores nesse município providenciou mudanças nas concepções e práticas alimentares das crianças. Isso fica claro no depoimento das merendeiras, já que atestam a melhor qualidade, frequência e diversidade dos produtos, determinando maior aceitação e consumo por parte dos alunos.
Eles comem muito mais. O milho verde é um deles, o enlatado não vai, mas o milho verde não sobra um grãozinho. Olha no prato e não sobra nada. O natural eles consomem o artificial não. $O$ extrato foi substituído pelo tomate, que a gente usa muito e pelo colorau. E eles aceitam e comem. Tiravam e colocavam do ladinho, hoje mais ninguém tira mais nada do prato. É raro uma criança deixar no prato. Tu gasta tudo, não sobra nada. O balde de sobras não tem mais. Acho que foi em função da melhora do produto, mas também da mão da pessoa, bem feito, fazer com amor. Dá mais trabalho, dá, mas fazendo com amor... (L. K. M., V.K., R. I. B., merendeiras).

Essa política acaba por realimentar esse mercado, na medida em que constrói paladares para alimentos produzidos localmente, por terem eles características exclusivas e/ou apreciadas pelos futuros consumidores. Nessa direção, torna-se importante destacar as contribuições dessa prática na construção de mercados para agricultores familiares locais e suas consequências, das quais citam-se as principais: a escolha por formas de plantio e produção diferenciados como os alimentos orgânicos e tradicionais, levando à promoção dessas estratégias; o incentivo à organização, à cooperação e à formalização; e a garantia da venda dos gêneros produzidos, com o aumento da renda e, provavelmente, diminuição do êxodo rural.

O conceito de qualidade atribuído aos gêneros alimentícios, além dos supracitados, tem sido associado também à questão ambiental e, com ela, à valorização de técnicas de produção "amigas da natureza". A título de exemplificação, o município de Dois Irmãos adquire o "néctar de uva produzido a partir de uvas orgânicas, e extraído a vapor". Segundo a nutricionista, além de a uva ser orgânica, o suco produzido pelo produtor daquele município distingue-se dos demais pela forma artesanal de extração do sumo, o que permite um alto grau de resveratrol, substância associada à diminuição do colesterol e à prevenção de doenças cardiovasculares [23]. Liga-se a questão de saúde com a questão ambiental que, segundo Lang e Heasman [11], fundamentam um novo paradigma de políticas alimentares que trabalham com a natureza e não sobre a natureza, contribuindo para a viabilização de mercados para esses tipos de produção. Em relação às questões ambientais, embora não pareçam, a princípio, ser determinantes da motivação dessas iniciativas, aparecem como resultados positivos, não só por estarem associadas aos métodos e processos de produção, mas também, pela diminuição das distâncias percorridas da produção até o consumo final.

Além disso, um dos principais fatores de sucesso para a construção desses mercados também acaba beneficiando os próprios produtores, ou seja, a 
necessidade de organização da produção dentro da propriedade, da cooperação entre os agricultores, deles com suas entidades representativas e, finalmente, deles com o poder público para acessarem os mercados. Isso lhes empodera, na medida em que obtêm mais condições de sobrevivência e reprodução. Essa experiência também demonstra que, na obtenção do sucesso na tentativa de aquisição de alimentos de produtores locais, as entidades representativas, como as de Assistência Técnica (Emater) e Sindicatos Rurais, foram fundamentais como mediadores do processo. Elas viabilizaram em grande medida as relações entre agricultores e Estado, por um lado, assessorando e auxiliando os produtores e, por outro, levando suas necessidades às instituições públicas, pressionando-as ou propondo ações para facilitarem o acesso deles ao mercado. A alimentação escolar favoreceu esse vínculo, no sentido de que foi a partir dessa mobilização que mais produtores interessaram-se na formalização de sua produção mediante Registros de Inspeção Municipal. A possibilidade de um novo mercado para a venda de seus produtos, também estimulou as duas associações de agricultores (apicultores e cunicultores) que, atualmente, têm representantes no Conselho de Alimentação Escolar e, com isso, condições de participarem na tomada de decisões do Serviço.

Por outro lado, enfatizando a importância desse Programa em relação à diminuição da pobreza e do êxodo rural, embora ainda seja precoce avaliar os impactos concretos dessas práticas, os relatos da experiência deste caso não só admitem a diminuição do êxodo rural, como também, a sua inversão, isto é, a ocorrência de agricultores que deixaram o trabalho na indústria coureiro-calçadista, para dedicarem-se exclusivamente à propriedade rural. A garantia da comercialização de seus produtos permitiu-lhes perspectivas de melhorias na renda, nos investimentos nos processos de produção e, também, na manutenção da família no meio rural.

Em alguns casos é uma das principais fontes. Sem este mercado perderiam em torno de 50\%, alguns em torno de 30 a $40 \%$. Se não tivessem a merenda teriam que fazer um novo mercado para poder compensar ou diminuir a sua renda. Incentiva (a permanência da família na agricultura), porque uma das grandes dificuldades em manter-se no meio rural é a comercialização. E como o programa dá uma garantia, isso dá estabilidade, dá uma receita e os membros então se fixariam. Aqueles que aderissem ao programa iriam precisar de 2 a 3 vezes mais pessoas para isso e não precisariam então de outro tipo de trabalho (P. J. B., STR).

Percebe-se nos discursos acima que todo o processo de construção de um novo modelo centra-se em uma economia da qualidade, e envolve o estabelecimento de formas de organização que pontuam a intensificação e colaboração entre consumo e produção. Central nesse construto, o papel do Estado e de seu poder em definir por intermédio de suas políticas e de seus programas de aquisições de alimentos, modelos diferenciados de abastecimento alimentar.

\section{Conclusões e lições a serem extraídas: o que ensina o caso de Dois Irmãos?}

A partir da experiência analisada, podem-se extrair algumas lições sobre o modo como esse pequeno município conseguiu suplantar barreiras e efetivar as compras para a alimentação escolar diretamente dos agricultores familiares de seu território. Por isso, a experiência pode ser vista como uma lição de como é possível reconectar a produção, neste caso a oferta de alimentos pelos agricultores locais, ao consumo de alimentos, representado pelos alunos beneficiários do PAE.

Como visto, o Estado tem providenciado, na última década, políticas de segurança alimentar e nutricional que apoiam a aproximação entre consumidores e produtores no nível local, porém, ao analisar o PAE, verifica-se a dificuldade em efetivá-las. Mesmo diante da nova legislação que incentiva a compra de produtos da agricultura familiar para a alimentação escolar em todo País, este caso remete-nos a algumas considerações.

Em primeiro lugar, há a necessidade da desburocratização dos mecanismos de acesso a esse mercado, diminuindo os custos de transação envolvidos. Mesmo que uma nova forma de aquisições públicas tenha sido criada especificamente para o agricultor familiar, ela não terá êxito, se continuar complexa em sua execução. Os próprios agricultores evidenciam que, para acessar esse mercado, é necessário um mínimo de discernimento para conseguir ultrapassar as barreiras burocráticas e que, nesse sentido, muitos estariam aquém dessa capacidade. Essas exigências desfavoreceriam, em última análise, os produtores em condições mais precárias, permanecendo à margem do processo, mesmo com as adequações e apoio dado pela gestão pública local.

Em segundo lugar, a simplificação do processo ao ato puro, simples e conhecido de produzir, contrapõese à sua complexificação, qual seja, o ato de produzir, adicionado às exigências de legalizar, gerenciar, organizar, cooperar, vender, distribuir etc. Nas palavras de Weber [24], "os obstáculos que enfrenta o camponês que deseja tornar-se um agricultor moderno levam à 
separação entre a propriedade e a administração". Portanto, o agricultor que deseja vender para a alimentação escolar tem a necessidade de organizar-se interna e externamente à sua propriedade, fato que pode gerar a desistência de grande parte deles. Isso chama a atenção para a análise de organização e de interfaces entre os agricultores, seus mediadores e o poder público que pode favorecê-los ou não. Abre-se nessa discussão um amplo debate sobre as questões organizativas e de cooperação entre eles. Salienta-se a forma diferenciada com que cada tipo de agricultor reage frente às intervenções estatais e, portanto, o cuidado que se deve tomar com as exigências feitas em relação a isso. Esse exemplo deixa claro que, antes de realizarem modificações e investirem numa mudança para acessar um novo mercado, os agricultores precisam experimentálo, percebendo se ele é ou não seguro, vantajoso, viável e se tem condições de abastecê-lo e de que forma. Só depois dessa constatação que eles reformulam ideias e atitudes, readequando-se e investindo numa organização formal ou na legalização.

Relativamente à legalização, e em terceiro lugar, esse foi um ponto referenciado por quase todos os agricultores como dificuldade em acessar o mercado institucional. Assim, um dos desafios que se impõem, principalmente depois da obrigatoriedade legal da aquisição de alimentos da agricultura familiar é a regulação da qualidade. O que, afinal, considera-se um produto de qualidade e quais devem ser as exigências sanitárias relativas à produção de baixa escala? Sem essa revisão normativa, muitos dos produtos processados pela agricultura familiar não poderão ser adquiridos por esse mercado institucional.

No entanto, o exemplo do município descrito, demonstra a importância da coesão e da interação social entre os atores da sociedade civil e do Estado para a implementação das políticas de forma mais efetiva, alcançando os benefícios a que se propõem. Para isso, é importante a governança concretizada a partir do diálogo entre os atores da sociedade civil e do Estado. Além disso, a reconexão da cadeia alimentar que se realiza entre produtores e consumidores por intermédio da proximidade constituem relações de exigências, negociações, trocas e suportes, construindo e consolidando relações pautadas em uma moral que transcende o âmbito econômico. $\mathrm{Na}$ fala dos produtores, há a necessidade de abastecer o mercado da merenda escolar com produtos de qualidade pelo diferencial em termos não só das concorrências (que diminuem), mas também pelo seu valor associado à saúde, ao meio ambiente e à cultura alimentar. Já na fala dos consumidores, há a necessidade de auxiliar os pequenos agricultores locais, para que possam sentir-se valorizados e obter seu sustento.

Os Conselhos Municipais constituem-se como espaços propícios para esse diálogo. Como visto acima, são eles que providenciam o encontro entre os diversos atores, e que permitem avançar em relação à superação das barreiras e em direção à governança do processo. A aproximação entre os interesses da sociedade e do setor público dentro desses Conselhos cria relações de confiança e de mútuo respeito e proporciona conhecimentos, concertamentos e benefícios para ambas as partes.

Vislumbra-se com isso, sementes de um modelo de desenvolvimento que promove não só crescimento econômico, mas também justiça social, saúde e conservação ambiental. Com isso, conclui-se que o Programa de Alimentação Escolar, além das potencialidades suprarreferidas, tem um grande potencial no que diz respeito à reunião de debates até aqui feitos separadamente, entre os problemas associados à produção e ao desenvolvimento rural e aqueles associados ao consumo e à saúde pública, abrindo uma ampla agenda de estudos e investigações que vão ao encontro das políticas de SAN.

\section{Referencias Bibliográficas}

1. Wang Y, Monteiro CA, Popkin BM. Trend of obesity and underweight in older children e adolescents in the USA, Brazil, China and Russia. Am J Clin Nutr. 2002; 75:971-7.

2. França CG, Del Grossi ME, Marques VPMA. O censo agropecuário 2006 e a agricultura familiar no Brasil. Mimeo; 2006.

3. Long N. From paradigm lost to paradigm regained? The case for an actor-oriented sociology of development. In: Long $\mathrm{N}$, Long, A (ed.). Battlefields of knowledge: the interlocking of theory and practice in social research and development. London: Routledge; 1992.

4. Long N. Sociología del desarrallo: una perspective centrada en el ator. Mexico: Colsan/Ciesas; 2007.

5. Sonnino R, Marsden TK. Beyond the divide: Rethinking relations between alternative and conventional food networks in Europe. Journal of Economic Geography. 2006; 6:181-189.

6. Callon M, Méadel C, Rabeharisoa V. The economy of qualities. Economy and Society. 2002; 31:194217. 
7. Goodman D. The quality 'turn' and alternative food practices: reflections and agenda. Journal of Rural Studies. 2003;19:1-7.

8. Morgan K. Greening the realm: sustainable food chains and the public plate. Regional Studies, 2007.

9. Morgan K. School meals and sustainable food chains the role of creative public procurement. Cardiff: Cardiff University; 2004.

10. Lang T, Heasman M. Food wars: the battle for minds, mouths and markets, London: Earthscan; 2004.

11. Minayo MC. O desafio do conhecimento. Pesquisa qualitativa em saúde. São Paulo: Hucitec; 1996.

12. Schneider S. (org.). A diversidade da agricultura familiar. Porto Alegre: Editora da UFRGS; 2006.

13. Guizzo BS, Krziminski CO, Oliveira DLLC. O software QSR NVivo 2.0 na análise qualitativa de dados: ferramenta para a pesquisa em ciências humanas e da saúde. Revista Gaúcha de Enfermagem. 2003; 24(1):53-60.

14. Schneider S. Economia, sociedade e cultura em Dois Irmãos nos últimos 50 anos: como construímos o que somos e para onde vamos? In: Dreher M, Mugge E. (org.). Dois Irmãos: dos primórdios ao cinquentenário de emancipação 2009. São Leopoldo: Oikos; 2009.

15. Schneider S. Agricultura familiar e industrialização: plutiatividade e descentralização industrial no Rio Grande do Sul. 2. ed. Porto Alegre: Editora da UFRGS; 2004.

16. Triches RM, Giugliani ERJ. Obesidade, práticas alimentares e conhecimentos de nutrição em escolares. Revista de Saúde Pública. 2005; 39:541547.

17. Manual sobre Alimentação Escolar. Porto Alegre: Emater/RS-Ascar; Fetag; Prefeituras Municipais dos Vales dos Rios dos Sinos e Paranhana/Encosta da Serra; 2006, 58 p.

18. Morgan K, Morley A. Relocalising the food chain: the role of creative public procurement. Cardiff: Cardiff University; 2002.

19. Amin A, Cohendet P. Architectures of knowledge: firms, capabilities, and communities. New York: Oxford; 2004.

20. Stuiver M, Leeuvis C, Ploeg JDV. The power of experience: farmer's knowledge and sustainable innovations in agriculture. In: Ploeg JDV,
Wiskerke JSC. Seeds of transition. Assen: Van Gorcumm; 2004.

21. Goodwin M. Rural governance: a review of relevant literature. Wales: University of Wales; 2003.

22. Giddens A. Social theory and modern sociology. Cambridge: Polity Press; 1987.

23. Gestão eficiente da merenda escolar: histórias gostosas de ler e boas de copiar. ONG Ação Fome Zero, vol. 2; 2007.

24. Weber M. Capitalismo e sociedade rural na Alemanha. In: Gerth HH, Mills CW (org.). Ensaios de Sociologia. Rio de Janeiro: Guanabara; 1982. 